\title{
Role of B Cells in Rheumatic Autoimmune Disease
}

\author{
Vanessa Hogan, Gillian Wheater, Christiaan Huigens, Thomas Hügle and Jacob M. van Laar*
}

Musculoskeletal Research Group, Institute of Cellular Medicine, Newcastle University, Newcastle upon Tyne, UK

\begin{abstract}
There is increasing evidence that B cells can play important roles in the pathogenesis of various autoimmune diseases, either by autoantibody secretion, production of proinflammatory cytokines or autoantigen presentation. An increasing number of B cell directed therapies are in development as a possible treatment strategy of rheumatic autoimmune diseases, such as Rituximab which targets the B cell specific CD20 surface marker. This article provides an overview of the principal understandings of B cell immunology in autoimmunity and selected rheumatic autoimmune diseases.
\end{abstract}

Keyword: B cells, Rheumatic autoimmune disease, Autoantibody, Cytokine, B cell depletion, Rituximab

\section{INTRODUCTION}

$\mathrm{B}$ cells are derived from haematopoietic stem-cell precursors in the bone marrow which progress into pro $\mathrm{B}$ cells, pre B cells, immature B cells and finally mature B cells. B cells can produce highly specific antibodies. Specific markers, such as CD20, CD27, BAFF-R (B cell activating factor receptor) and CD138, identify the transitional phases of B cells from stem cells to plasma cells [1]. CD20, the target for the $\mathrm{B}$ cell depleting drug Rituximab, is expressed on all B cells except on the pro B cells and the antibody secreting plasma cells. Each mature B cell leaves the bone marrow with unique antigen specific B cell receptors (BCR) on its surface and migrates towards follicular lymphoid tissue [2]. If the $\mathrm{BCR}$ on a mature $\mathrm{B}$ cell encounters its antigen, the $\mathrm{B}$ cell proliferates and differentiates into antibody producing plasma cells or long lived memory B cells.

B cells are essential for the protection against microbes, but can also play an important role in the pathogenesis of various autoimmune diseases. This review gives an overview of the principle understandings of $\mathrm{B}$ cell immunology in autoimmunity and selected autoimmune diseases.

\section{ROLE OF B CELLS IN AUTOIMMUNE DISEASE}

In a healthy immune system, B cells are tolerant of self antigens and will only bind to non self antigens. B cells acquire this immune tolerance to self antigens during their development in the bone marrow, where immature B cells that recognise self antigens are removed by apoptosis. Additionally, B cells that recognise soluble self antigens lose their ability to respond and are prevented from migrating to follicular lymphoid tissue. Autoimmune diseases result when such mechanisms fail, resulting in the generation of pathogenic, self reactive $\mathrm{B}$ cells.

Recent studies into B cell function have implicated additional roles for B cells other than autoantibody production.

*Address correspondence to this author at the Professor of Clinical Rheumatology, Musculoskeletal Group, Institute of Cellular Medicine, Newcastle University, Newcastle Upon Tyne, NE2 4HH, UK; Tel: +44 191222 7139; Fax: +44 191222 5455; E-mail: v.e.hogan@newcastle.ac.uk

\subsection{Autoantibody Production}

Antibodies function both as a natural barrier to infection and as a humoral component of adaptive responses to pathogens however autoantibody production can have pathogenic consequences in autoimmune diseases.

Patients with rheumatoid arthritis (RA) often present with abnormal levels of autoantibodies, commonly rheumatoid factor (RF) and anti-cyclic citrullinated peptide (anti-CCP) antibodies. RF is specific to the Fc portion of other immunoglobulin molecules whereas anti-CCP antibodies bind citrullinated peptides. Both antibodies have been found to precede the onset of RA symptoms and are associated with a more severe disease outcome [3]. Neither factor is $100 \%$ sensitive or specific to the diagnosis of RA. For instance, RF is present in $50-80 \%$ of patients with RA, but also approximately $10 \%$ of the general population. Anti-CCP antibodies are more specific to RA, with a limited proportion of individuals in the general population testing positive [3].

The production of antibodies to DNA, RNA and other nuclear antigens are the serologic hallmarks of systemic lupus erythematosus (SLE) [4]. Of these antibodies, antidsDNA antibodies are used as markers for diagnosis and prognosis of SLE. In animal models, anti-dsDNA expression is the defining immunologic feature of the disease [5]. The high amount of autoantibodies and polyclonal stimulation of $\mathrm{B}$ cells lead to the formation of immune complexes, which in turn cause organ damage such as renal failure. Examples of directly pathogenic autoantibodies are the anti-neutrophil cytoplasmic antibodies (ANCA) which are associated with vasculitis and ulcerative colitis [6].

In systemic Sclerosis ( $\mathrm{SSc}$ ), anti-topoisomerase (anti-Scl70) autoantibodies are associated with the diffuse disease subset whereas anti-centromere antibodies are typically found in the limited form. A pathogenic effect has not been described for either of these autoantibodies. On the other hand, autoantibodies directed against endothelial cells have shown to induce apoptosis [7] and autoantibodies directed against the PDGF receptor stimulate the collagen expression in fibroblasts in SSc [8]. 


\subsection{Antigen Presentation}

During the initiation of the immune response B cells can also act as antigen presenting cells [9]. The requirement of B cells in the initiation of $\mathrm{T}$ cell immune responses was first demonstrated in mice lacking Ig positive cells and serum Ig. These mice were found to have severely impaired $\mathrm{T}$ cell proliferative responses to the relevant antigen [10]. Antigen specific interactions between $\mathrm{B}$ and $\mathrm{T}$ cells may require the antigen to be first internalised by the $\mathrm{BCR}$, processed and then presented in an MHC restricted manner to $\mathrm{T}$ cells [11]. Recent studies which have depleted mature CD20+ B cells from mice leaving otherwise intact immune systems demonstrated that $\mathrm{B}$ cells are needed for maximum CD4+ $\mathrm{T}$ cell activation during immune responses to autoantigens [12]. A significant role for B cells in autoimmune disease was demonstrated in these B cell depleted mice as autoantigen challenge reduced antigen specific CD4+ T cell activation. On the other hand, the priming of autoreactive $\mathrm{B}$ cells is $\mathrm{T}$ cell independent and toll like receptor dependent [13].

\subsection{B Cells and Cytokine Production}

While critical for normal immune system development, B cells are also important for its maintenance. B cells can produce a wide spectrum of cytokines under inflammatory conditions, including IL-4, IL-6, TGF- $\beta$ and IFN- $\gamma$. B cells may also play a regulatory role by modulating the production of IL-10, an anti inflammatory cytokine which can suppress harmful immune responses resulting in the prevention of innate cell mediated inflammatory responses [14]. It is thought that IL-10 acts by suppressing both Th1 and Th2 polarisation and inhibiting antigen presentation and proinflammatory cytokine production by monocytes and macrophages [15]. In the collagen induced arthritis mouse model, IL10, produced by the B cells had a positive affect on the autoimmune disease, downregulating the disease severity [14]. Hence B cell depletion may in some cases be detrimental to the autoimmune disease, possibly due to the lack of IL10 production by B cells, although clinical evidence for this in humans has not yet been obtained.

\subsection{B Cells and Apoptosis}

Apoptosis has shown to be involved in the induction of autoimmunity. The uptake of apoptotic cell material by antigen presenting cells can initiate an immune response [16]. As demonstrated in animal models, the induction of an inflammatory reaction by apoptotic cells is inhibited by IL-10 producing regulatory $\mathrm{B}$ cells [17].

\section{B CELL DEPLETION THERAPY}

As it has become more obvious that B cells contribute substantially to multiple human autoimmune diseases, B cell targeted therapies focused on restoring normal B cell function and eliminating pathogenic autoantibodies are beginning to reduce the reliance on immunosuppressive drugs.

The first B cell depleting agent, Rituximab (RTX) was approved in 1997 for treatment of B cell malignancies [18]. In 2001, based on the hypothesis that autoantibodies from antibody secreting plasma cells were closely associated with disease pathogenesis, the first study was published showing promising effects of RTX in the treatment of patients with rheumatoid arthritis. As circulating autoantibodies are a common feature in several other autoimmune diseases, clinical trials into B cell depleting therapies are now widely assessed for safety and efficacy for treatment of these autoimmune diseases.

RTX is a chimeric mouse-human monoclonal antibody that specifically targets the transmembrane protein $\mathrm{CD} 20$ of $B$ cells [19]. The binding of RTX to CD20 leads to significant depletion of peripheral B cells from pre B cells to memory B cells, sparing other cell lineages such as stem cells, pro $B$ cells and plasma cells [20]. The therapeutic importance of this selectivity is that there is no depletion of stem cells, thus B cell recovery is not impaired and immunoglobulin secretion by plasma cells is maintained resulting in effective targeted immune effector depletion without immunesuppression.

Another method of treatment is to deprive B cells from signals for their growth and survival resulting in cell death. One such treatment is BAFF (B cell activating growth factor) targeting therapy. BAFF is a member of the TNF family which binds to $\mathrm{B}$ cells and stimulates their proliferation and survival. Elevated levels of BAFF have been found in the serum of patients with autoimmune disease [21]. It is thought that BAFF prevents apoptosis of self reactive B cells therefore high levels of BAFF will maintain self reactive B cells in autoimmune disease [22].

\subsection{Mechanism of Action of Rituximab}

Multiple mechanisms are proposed for RTX mediated B cell depletion. These effector mechanisms may act individually or collectively to deplete B cells depending on the disease pathology. One such mechanism is induction of complement dependent cytotoxicity and complement dependent cellular cytotoxicity on target B cells. The difference in susceptibility of malignant and pathological B cells to RTX may depend on the expression of complement regulatory proteins (CRP) such as CD55, CD46 and CD59 on target cells [23]. Another possible mechanism of action of RTX is antibody dependent cellular cytotoxicity. RTX is thought to induce the elimination of B cells through natural killer (NK) cells [24]. Finally opsonization of B cells by RTX may also induce the clearance of B cells through phagocytosis by the reticuloendothelial system. This system may also aid in the clearance of apoptotic B cells after RTX treatment [25].

All of these possible mechanisms may contribute to RTX mediated B cell depletion, however it is thought that complement mediated B cell depletion is the main mechanism involved.

\subsection{Mechanism of Action of BAFF Targeting Therapy}

The mechanism of B cell depletion using BAFF antagonists is very different to B cell depletion using RTX. BAFF antagonists induce cell death by blocking the survival signal for B cells rather than antibody and complement dependent cytotoxicity, resulting in only a $40 \%$ peripheral B cell depletion [26]. However BAFF targeted therapy will be more effective on self reactive B cells as these B cells are highly dependent on BAFF for maintenance, whereas autoantibody producing plasma cells are not affected by RTX as they do not possess the CD20 surface marker. 


\section{B CELL DEPLETION IN RHEUMATOID ARTHRI- TIS}

RA is a chronic systemic inflammatory disease, mainly characterised by symmetrical synovitis of diarthrodial joints resulting in pain, stiffness and loss of function. RA has a wide clinical spectrum varying from mild symptoms to severe inflammation and joint damage. Additionally a wide variety of extra-articular manifestations may develop, for example rheumatoid nodules and interstitial lung disease [27]. Macrophages, $T$ cells and multiple cytokines may all be involved in the pathogenesis. Several hypothesised mechanisms include $\mathrm{B}$ cell dependent activation of synovial $\mathrm{T}$ cells, B cell secretion of proinflammatory cytokines and B cell production of the rheumatic factor autoantibody.

In patients with RA, B cell depletion using RTX shows a significant improvement in joint inflammation [28]. A recent study reported that RTX led to a rapid and complete depletion of all $\mathrm{B}$ cells in peripheral blood of RA patients. It was also found that $\mathrm{CD} 20+\mathrm{B}$ cells in bone marrow were completely depleted at 12 weeks after therapy [29]. Finally the same group showed that all CD20+ B cells were eradicated in the synovium. In a multicentre, randomised, double blind controlled study, an improvement in disease symptoms and activity was seen after treatment with RTX in patients with active RA. Furthermore, rheumatoid factor levels were decreased in the RTX group, suggesting that positivity for rheumatoid factor is associated with more active and aggressive disease [30].

Recent data suggests that after RTX treatment, the phenotype of re-emerging peripheral B cells are mainly CD5+, CD38high naïve B cells [31]. Thus B cell depletion could act by resetting the immune system by replacing the autoreactive $B$ cells with naïve nonreactive $B$ cells.

BAFF antagonists have also been investigated for the treatment of RA in a mouse model. Administration of BAFF antagonists into the Collagen Induced Arthritis mouse model of RA reduced tissue damage and prevented disease progression [32].

\section{B CELL DEPLETION IN SYSTEMIC LUPUS ERYTHEMATOSUS}

Systemic lupus erythematosus (SLE) is a complex and heterogenous disorder, often with multiple sites of organ involvement and has a progressive as well as relapsing/remitting nature in many patients [33]. It can present as a mixture of mild skin or musculoskeletal and haematological signs and symptoms, but also may involve more serious central nervous system involvement and organ damage [34].

RTX efficacy for refractory SLE appears promising and well tolerated in most patients. Preliminary results from a study of six patients with SLE on RTX showed that RTX reduced B cell numbers, with repletion occurring 6-9 months after treatment. Results also showed that RTX sometimes reduced anti-dsDNA antibody titers. Symptoms of SLE, such as fatigue and serositis responded particularly well [35]. In a more recent study by Looney et al. [36], 18 longstanding SLE patients were treated with 3 different RTX doses. Results showed effective B cell depletion with the higher RTX dose but with high variability. However, the levels of antidsDNA did not change significantly in this study. Sfikakis et al. [37] then went on to treat ten SLE patients with class III and IV nephritis. Results showed both B cells and relevant autoantibodies (antinuclear and anti-dsDNAa antibodies) decreased after treatment, with an $80 \%$ rate of clinical remission after 3 months. These results and those from a recent retrospective single-centre analysis of 50 patients [38], would suggest that $\mathrm{B}$ cell depletion is a major advance in the treatment of patients with SLE. These results need to be confirmed through prospective, controlled, randomised trials.

BAFF antagonists have also been investigated for the treatment of SLE in both mouse models and humans. Administration of a BAFF antagonist into a mouse model of SLE was found to have a positive effect on disease symptoms and prevent disease progression [39]. Also development of a BAFF antagonist, Belimumab is currently under clinical trial in SLE patients. Preliminary data showed Belimumab was effective and well tolerated in these SLE patients and reduced antibody levels [40].

Epratuzumab is a monoclonal antibody directed against the B cell surface antigen CD22. An initial trial on 14 subjects with SLE demonstrated that this drug was well tolerated with a modest decrease in B cells [41].

\section{B CELL DEPLETION AND SYSTEMIC SCLEROSIS}

Systemic Sclerosis is a connective tissue disease characterised by inflammation, vascular endothelial dysfunction and tissue fibrosis due to an imbalance between collagen production and degradation. There are two different clinical subtypes of SSc, the limited form (lcSSc) which is characterised by skin thickening of the neck, face and distal aspects of the limbs and an increased prevalence of isolated pulmonary hypertension and the diffuse form (dcSSc) which also affects visceral organs including lungs, heart and kidneys [42].

A pilot study in 15 patients with dcSSc treated with RTX showed depletion of both dermal and circulating B cells, however no positive effect on skin fibrosis or autoantibody titer was observed [43]. In the tight skin mouse model of SSc, B cell depletion with RTX reduced skin fibrosis, autoantibody titer and hypergammaglobulinemia. However these positive effects were only observed in the early phase of the disease and not the chronic phase [44]. These results would suggest that B cells are involved in the initiation of the disease but are not required for disease maintenance.

\section{B CELL DEPLETION AND VASCULITIS}

Primary vasculitis predominantly affects small blood vessels and is associated with ANCA autoantibodies. As B cells are present at sites of vasculitic inflammation current therapies aim to focus more on B cell depletion [45]. B cell depletion with RTX led to a complete remission in 9 out of 10 patients with refractory vasulitis [46]. In a second clinical trial, B cell depletion led to complete remission in 9 out of 10 patients [47]. Both trials demonstrated variable relapse rates with relapses occurring in approximately $25 \%$ of patients after 12-16 months.

\section{B CELL DEPLETION AND ANKYLOSING SPON- DYLITIS}

Chronic inflammation in ankylosing spondylitis (AS) primarily affects the axial skeleton, but larger peripheral joints may also be involved. Fibrosis can result in complete 
ankylosis of the involved joints [48]. As B cell depletion has now been found to be an effective treatment strategy for RA, the question is now whether Rituximab could be an appropriate therapeutic target in AS. In contrast to RA, no specific autoantibodies have been described in ankylosing spondylitis, however in patients with AS, B cells and plasma cells have been found to be abundant in the inflamed peripheral joint [48]. It has now been found that B cells not only can amplify autoimmune processes, but can also regulate immune reactions, mainly by production of IL-10 [49]. Evidence of these regulatory B cells has mainly been observed in mouse models of inflammatory bowel disease, a disorder that is closely associated with AS, however this regulatory function has not yet been proven in humans. It was recently reported that B cell depletion can induce psoriasis and even psoriatic arthritis [50], therefore B cell depletion may not only have beneficial, but also detrimental effects in AS.

\section{CONCLUSION}

B cells play an important role in autoimmune disease, not only by autoantibody production but also by cytokine release, antigen presentation and T cell activation. Anti-B cell therapy, in particular treatment with Rituximab, is a promising approach for immunotherapy of rheumatic diseases, and has the potential to produce long lasting benefits.

\section{REFERENCES}

[1] Dalakas MC. B cells as therapeutic targets in autoimmune neurological disorders. Nature Clin Pract 2008; 4 (10): 557-67.

[2] Hardy RR, Hayakawa K. B cell development pathway. Ann Rev Immunol 2001; 19: 595-621.

[3] Mewar D, Wilson AG. Autoantibodies in rheumatoid arthritis: a review. Biomed Pharmacother 2006; 60 (10): 648-55.

[4] Arbuckle MR. Development of autoantibodies before the clinical onset of systemic lupus erythematosus. N Engl J Med 2003; 349: 1526-33

[5] Ardoin SP, Pisetsky DS. Developments in the scientific understanding of Lupus. Arthritis Res Ther 2008; 10 (5): 1-8.

[6] Xiao $\mathrm{H}$, Heeringa $\mathrm{P}$, Hu $\mathrm{P}$, et al. Antineutrophil cytoplasmic autoantibodies specific for myeloperoxidase cause glomerulonephritis and vasculitis in mice. J Clin Invest 2002; 110 (7): 95563.

[7] Lunardi C, Bason C, Navone R, et al. Systemic Sclerosis immunoglobulin $\mathrm{G}$ autoantibodies bind the human cytomegalovirus late protein UL94 and induce apoptosis in human endothelial cells. Nat Med 2000; 6 (10): 1183-6.

[8] Baroni SS, Santillo M, Bevilacqua F, et al. Stimulatory autoantibodies to the PDGF receptor in systemic sclerosis. N Engl J Med 2006; 354 (25): 2667-76.

[9] Constant S, Schweitzer N, West J, Ranney P, Bottomly K. B lymphocytes can be competent antigen presenting cells for priming CD4+ T cells to protein antigens in vivo. J Immunol 1995; 155: 3734-41.

[10] Ron Y, De Baetselier P, Gordon J, Feldman M, Segal S. Defective induction of antigen-reactive proliferating $\mathrm{T}$ cells in $\mathrm{B}$ cell deprived mice. Eur J Immunol 1981; 11: 964-8.

[11] Ron Y, Sprent J. T cell priming in vivo: a major role for B cells in presenting antigen to T cells in lymph nodes. J Immunol 1987; 138: 2848-56.

[12] Bouaziz JD, Yanaba K, Venturi GM, et al. Therapeutic B cell depletion impairs adaptive and autoreactive CD4+ T cell activation in mice. Proc Natl Acad Sci USA 2007; 104: 20882-7

[13] Herlands RA, Christensen SR, Sweet RA, Hershberg U, Shlomchick MJ. T cell independent and toll like receptor dependent antigen-driven activation of autoreactive B cells. Immunity 2008; 29 (2): 249-60.

[14] Mauri C, Gray D, Mushtaq N, Londei M. Prevention of arthritis by interleukin 10 producing B cells. J Exp Med 2003; 197: 489-501.

[15] Asadullah K, Sterry W, Volk HD. Interleukin 10 therapy review of a new approach. Pharmacol Rev 2003; 55: 241-69.
[16] Gallucci S, Lolkema M, Matzinger P. Natural adjuvants endogenous activators of dendritic cells. Nat Med 1999; 5 (11): 1249-55.

[17] Gray M, Miles K, Salter D, Savill J. Apoptotic cells protect mice from autoimmune inflammation by the induction of regulatory B cells. Proc Natl Acad Sci USA 2007; 104 (35): 14080-5.

[18] Coiffier B, Lepage E, Briere J, et al. CHOP chemotherapy plus rituximab compared with $\mathrm{CHOP}$ alone in elderly patients with diffuse large B cell lymphoma. N Eng T Med 2002; 346: 235-42.

[19] Gurcan HM, Keskin DB, Stern JN, Nitzberg MA, Shekhani H, Ahmed AR. A review of the current use of rituximab in autoimmune diseases. Int Immunopharmacol 2009; 9 (1): 10-25.

[20] Panayi GS. B cell directed therapy in rheumatoid arthritis clinical experience. J Rheumatol suppl 2005; 73: 19-24.

[21] Groom J, Kalled SL, Cutler AH, et al. Association of BAFF/BLys overexpression and altered B cell differentiation with Sjogren's syndrome. J Clin Invest 2002; 109:59-68.

[22] Sun J, Lin Z, Feng J, Li Y, Shen B. BAFF targeting therapy, a promising strategy for treating autoimmune diseases. Eur J Pharmacol 2008; 597: 1-5.

[23] Golay J, Zaffaroni L, Vaccari T, Lazzari M, Borleri GM, Bernasconi S. Biologic response of B lymphoma cells to anti-CD20 monoclonal antibody Rituximab in vitro: CD55 and CD59 regulate complement mediated cell lysis. Blood 2000; 95 (12): 3900-8.

[24] Cardarelli PM, Quinn M, Buckman D, et al. Binding to CD20 by anti B1 antibody of $F(a b)$ (2) is sufficient for induction of apoptosis in B cell lines. Cancer Immunol Immunother 2002; 51 (1): 15-24.

[25] Lefebvre MI, Krause SW, Salcedo M, Nordin A. Ex vivo activated human macrophages kill chronic lymphocytic leukaemia cells in the presence of Rituximab: mechanism of antibody dependent cellular cytotoxicity and impact of human serum. J Immunother 2006; 29 (4): 388-97.

[26] Dall Era M, Chakravarty E, Wallace D, et al. Reduced B lymphocyte and immunoglobulin levels after atacicept treatment in patients with systemic lupus erythematosus: results of a multicenter phase $1 \mathrm{~b}$ double blinded placebo controlled dose escalating trial. Arthritis Rheum 2007; 56: 4142-50.

[27] Lawrence RC, Helmick CG, Arnett FC, Deyo RA, Felson DT, Giannini EH. Estimates of the prevalence of arthritis and selected musculoskeletal disorders in the United States. Arthritis Rheum 1998; 41 (5): 778-99.

[28] Leandro MJ, Cambridge G, Ehrenstein MR, Edwards JC. Reconstitution of peripheral blood B cells after depletion with rituximab in patients with rheumatoid arthritis. Arthritis Rheum 2006; 54: 61320.

[29] Teng YKO, Huizinga TWJ, Van Laar JM. Targeted therapies in rheumatoid arthritis: focus on rituximab. Biol Targets Ther 2007; 4: $1-9$.

[30] Edwards JC, Szczepanski L, Szechinski J, Filipowicz-Sosnouska A, Enery P, Close DR. Efficacy of B cell targeted with Rituximab in patients with Rheumatoid Arthritis. N Eng J Med 2004; 350: 2572-81

[31] Roll P, Palanichomy A, Kneitz C, Dorner T, Tony H. Regeneration of B cell subsets after transient B cell depletion using anti-CD20 antibodies in Rheumatoid arthritis. Arthritis Rheum 2006; 54 (8): 2377-86.

[32] Wang H, Marsters SA, Baker T, et al. TACI ligand interactions are required for $\mathrm{T}$ cell activation and collagen induced arthritis in mice. Nat Immunol 2001; 2: 632-7.

[33] Iam GK, Petri M. Assessment of systemic lupus erythematosus. Clin Exp Rheumatol 2005; 23 (Suppl 39): 5120-32.

[34] Gill JM, Quisel AM, Rocca PV, Walters DT. Diagnosis of systemic lupus erythematosus. Am Fem Physician 2003; 68: 2179-86.

[35] Leandro MJ, Edwards JC, Cambridge G, et al. An open study of B lymphocyte depletion in systemic lupus erythmatosus. Arthritis Rheum 2002; 46: 2673-7.

[36] Looney RJ, Anolik JH, Campbell D, Felgar RE, Young F, Arend LJ. B cell depletion as a novel treatment for systemic lupus erythematosus: a phase I/II dose escalation trial of rituximab. Arthritis Rheum 2004; 50: 2580-9.

[37] Sfikakis PP, Boletis JN, Lionaki S, Vigklis V, Fragiadaki KG, Iniotaki A. Remission of proliferative lupus nephritis following B cell depletion therapy is preceded by down regulation of the $\mathrm{T}$ costimularly molecule CD40 ligand: an open label trail. Arthritis Rheum 2005; 52: 501-13.

[38] Lu TY, Ng KP, Cambridge G, et al. A retrospective seven year analysis of the use of B cell depletion therapy in systemic lupus 
erythematosus at University College London Hospital: the first fifty patients. Arthritis Rheum 2009; 61 (4): 482-7.

[39] Gross JA, Johnston J, Mudri S, et al. TACI and BCMA are receptors for a TNF homologue implicated in B cell autoimmune disease. Nature 2000; 404: 995-9.

[40] Kahn K. Belimumab may be effective treatment for SLE. Medscape medical news 2007.

[41] Jacobi AM, Goldenberg DM, Hiepe F, Radbruch A, Burmester GR. Differential effects of epratuzumab on peripheral blood cells of patients with systemic lupus erythematosus versus normal controls. Ann Rheum Dis 2008; 67 (4): 450-7.

[42] Kraaij MD, Van Laar JM. The role of B cells in systemic sclerosis. Biologics 2008; 2 (3): 389-95.

[43] Lafyatis R, Kissin E, York M, et al. B cell depletion with Rituxi$\mathrm{mab}$ in patients with diffuse cutaneous systemic sclerosis. Arthritis Rheum 2009; 60 (2): 578-83.

[44] Hasegawa M, Hamoguchi Y, Yanaba K, et al. B lymphocyte depletion reduces skin fibrosis and autoimmunity in the tight skin mouse model for Systemic Sclerosis. Am J Pathol 2006; 169 (3): 954-65.
[45] Hiemstra TF, Jayne D. Newer therapies for vasculitis. Best Pract Res Clin Rheumatol 2009; 23: 379-89.

[46] Smith KG, Jones RB, Burns SM, Jayne DR. Long term comparison of rituximab treatment for refractory systemic lupus erythmatosus and vasculitis: remission, relapse and retreatment. Arthritis Rheum 2006; 54: 2970-80

[47] Stasi R, Stipa E, Del Poeta G, Amadori S, Newland AC, Provan D. Long-term observation of patients with anti-neutrophil cytoplasmic antibody-associated vasculitis treated with rituximab. Rheumatology (Oxford) 2006; 45 (11): 1432-6.

[48] Appel H, Kuhne M, Spiekerman S, et al. Immunohistologic Analysis of Zygapophyseal joints in Patients with Ankylosing Spondylitis. Arthritis Rheum 2006; 54 (9): 2845-51.

[49] Mizoguchi A, Bhan AK. A case for regulatory B cells. J Immunol 2006; 176: 705-10.

[50] Dass S, Vital EM, Emery P. Development of psoriasis after B cell depletion wit rituximab. Arthritis Rheum 2007; 56: 2715-8.

(C) Hogan et al.; Licensee Bentham Open.

This is an open access article licensed under the terms of the Creative Commons Attribution Non-Commercial License (http://creativecommons.org/licenses/by-nc/3.0/) which permits unrestricted, non-commercial use, distribution and reproduction in any medium, provided the work is properly cited. 